\title{
The effect of intravenous tranexamic acid on preventing the progress of cerebral hemorrhage in patients with brain traumatic injuries compared to placebo: A randomized clinical trial
}

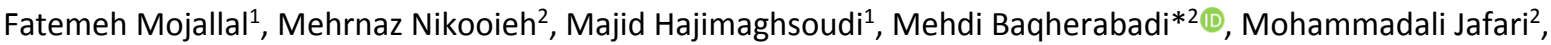 \\ Alireza Esmaeili², Naser Mohammad Karimi², Ehsan Zarepur ${ }^{3}$ \\ Received: 12 Feb 2019 \\ Published: 27 Aug 2020
}

\section{Abstract}

Background: Head trauma is one of the common reasons for patient attendance in the emergency ward. This study investigated the effect of tranexamic acid as a cheap, easily available antifibrinolytic drug on reducing the progress of cerebral hemorrhage compared to placebo.

Methods: This double-blind controlled clinical trial was performed on 120 traumatized patients presenting to the emergency room of Shahid Rahnemoon hospital during 2014-2015, Yazd, Iran. Those patients who met the inclusion criteria were randomly allocated into 2 groups. Group A received tranexamic acid, while group B received placebo parenterally. Finally, 56 patients in Group A and 44 in Group B were analyzed. The patients underwent brain CT scan and were followed up for ICU stay in days. Also, the number of patients who died during the first 7 days of hospitalization was recorded. The data were analyzed with SPSS20 using independent samples t test and chi-square test.

Results: The mean age of the patients was $41 \pm 20.27$ years. Also, 20 patients $(20 \%)$ were female and 80 were male $(80 \%)$. There was no significant difference between the drug group and placebo group in the rate of hemorrhage volume progress ( $\mathrm{p}=0.824)$. Regarding patients' ICU stay, the ICU stay of the tranexamic acid group decreased significantly compared to the placebo group ( $\mathrm{p}=0.001$ ). No significant difference was found between the intervention group and placebo group in the mortality rate of patients during the first 7 days of hospitalization $(\mathrm{p}=0.236)$.

Conclusion: Tranexamic acid has no effect on reducing cerebral hemorrhage volume in patients. Although this drug was not effective in reducing mortality rate in patients, it decreased their ICU stay.

Keywords: Trauma, Cerebral, Hemorrhage, Tranexamic acid, Clinical Trial

Conflicts of Interest: None declared

Funding: Shahid Sadoughi University of Medical Sciences

\section{*This work has been published under CC BY-NC-SA 1.0 license.}

Copyright $\odot$ Iran University of Medical Sciences

Cite this article as: Mojallal F, Nikooieh M, Hajimaghsoudi M, Baqherabadi M, Jafari M, Esmaeili A, Karimi NM, Zarepur E. The effect of intravenous tranexamic acid on preventing the progress of cerebral hemorrhage in patients with brain traumatic injuries compared to placebo: A randomized clinical trial. Med J Islam Repub Iran. 2020 (27 Aug);34:107. https://doi.org/10.47176/mjiri.34.107

\section{Introduction}

The brain is the most complex organ in the human body

Corresponding author: Dr Mehdi Baqherabadi, m.bagherabadi@ssu.ac.ir

1. Trauma Research Center, Shahid Sadoughi University of Medical Sciences, Yazd, Iran

2. School of Medicine, Shahid Sadoughi University of Medical Sciences, Yazd, Iran

3. Cardiology resident, PhD candidate, Isfahan Cardiovascular Research Center, Cardiovascular Research Institute, Isfahan University of Medical Sciences, Isfahan, Iran and any disease or damage to it can cause many problems.

\section{$\uparrow$ What is "already known” in this topic:}

Tranexamic acid has been studied in bleeding control and has had positive results in most cases. Also, tranexamic acid is an antifibrinolytic and anti-inflammatory drug that reduces mortality and morbidity in patients with bleeding.

\section{$\rightarrow$ What this article adds:}

This study examined the effect of tranexamic acid on preventing the progress of cerebral hemorrhage in patients with brain traumatic injuries, but unlike other studies, this drug was not effective in bleeding control. Nonetheless, the results of data analysis showed this drug reduced the number of hospitalization days in the ICU and reduced the costs of trauma patients. 
Cerebral trauma may be primarily induced by direct impact to the head or occur secondarily due to hypoxia, edema and inflammation, hypoglycemia, and oxidative stress. Intracranial hemorrhage is one of the complications of impact to the head, which appears in various forms depending on the site of bleeding. Various types of cerebral hemorrhage occur in about half of the patients who sustain head impact accounting for two-thirds of mortalities in these patients (1-4).

Regarding the fixed volume of the cranial cavity, the presence of any mass or lump, incidence of hemorrhage, edema, or inflammation which occur gradually around them, lead to increased intracranial pressure. This increased pressure gradually decreases the cerebral blood flow and results in ischemia and various types of cerebral hernia. Various methods are used to reduce intracranial pressure, including hyperventilation, osmotic drugs, diuretics, and CSF drainage, raising the patient's head by 30 degrees, the use of barbiturates group, and induction of hypothermia $(2,4)$.

Tranexamic acid is an antifibrinolytic drug of the antihemorrhagic family in therapeutic classification. This medicine is commercially available in capsule, tablet, and parenteral forms, with therapeutic daily dosage of $6 \mathrm{~g} /$ day. This drug prevents the activation of plasminogen competitively and hinders its conversion to plasmin. In higher doses, it directly inhibits the plasmin activity (4).

It is also used in various procedures, such as dental interventions, surgeries of urinary bladder and prostate gland, menorrhegia, treatment of congenital angioedema, and bleeding of anterior ophthalmic orbit due to impact. However, this drug is contraindicated in patients with subarachnoid hemorrhage or renal dysfunction $(4,5)$.

For injection purposes, this drug may be mixed with most infusion solutions, such as electrolyte, carbohydrate, amino acids, and dextran solutions. Moreover, scholars noticed the anti-inflammatory effects of tranexamic acid through inhibiting plasmin activity. Following this finding, this drug is being used as one treatment of swelling and sore throat (6).

This drug has attracted attention in recent years again and several studies have been conducted on its effect on controlling bleeding in various body parts with various clinical etiologies. More than 10 million people die or are hospitalized annually due to cerebral trauma worldwide (7). Given the age range involved in this condition, including the active stratum of the community, the higher prevalence of the trauma in moderate-to-low income countries, and the high cost of treating these patients due to long hospitalization, surgery, the need for ICU care, followed by the need for a variety of rehabilitation methods, the quality of life of many of these patients is significantly reduced.

Therefore, an effective, cost effective, and practical therapy is needed. Hence, tranexamic acid as a cost effective and easily available medicine with no significant complications reported so far was investigated in this clinical trial.

\section{Methods}

\section{The study population}

All the traumatized patients older than 18 years presenting to the emergency room of Shahid Rahnemoon hospital in Yazd, Central Iran, were screened for the inclusion criteria. The sample volume was set at 98 , considering type I error of 0.05 and type II error of $\% 20$, which was increased to 120 to enhance the validity of the study results.

In this clinical trial study (Iranian Clinical Trials Registration no.: IRCT2015090423890N1), 120 traumatized patients presenting to the ER of Shahid Rahnemoon hospital during June 2014 to June 2015 met the inclusion criteria. Due to craniotomy before the first 24 hour, 20 patients were excluded from the study, and ultimately 100 patients entered the study. The patients were assigned into groups $\mathrm{A}$ and $\mathrm{B}$ using the random numbers table (without awareness of the researcher or assessor). Group A received tranexamic acid, while group $\mathrm{B}$ received placebo parenterally. A total of 56 patients in Group A and 44 in Group B were analyzed.

\section{Inclusion and exclusion criteria}

The inclusion criteria were as follow: age older than 18 years; detection of cerebral hemorrhage in brain CT scan, including subdural hematoma, epidural hematoma, intracerebral hemorrhage, and intraventricular hemorrhage; absence of subarachnoid hemorrhage along with the hemorrhages mentioned above; passage of less than 8 hours after trauma incidence; negative history of taking anticoagulants; and negative history of blood coagulation system impairments, such as hemophilia or idiopathic thrombocytopenic purpura. The patients who underwent craniotomy less than 24 hours after entry into the study were excluded from the study.

\section{Data collection method}

The data were gleaned based on the variables under study using the designed checklists and were analyzed with SPSS20.

\section{Research procedures}

In this randomized clinical trial, 100 patients with cerebral trauma presenting to the ER of Shahid Rahnemoon hospital met the inclusion criteria of the study. Informed written consent was obtained from each patient and they underwent a double-blind treatment with tranexamic acid or placebo. The drug and placebo were drawn into similar syringes with equal volumes and coded. Random numbers table was used for randomization of the study. The patient and the researcher were unaware of the injection content. Distilled water was used as placebo. The hemorrhage volume in the primary cerebral CT scan of the patients was estimated by the following formula: $\frac{a \times b \times c}{2}$ where $\mathrm{a}=$ the greatest width of hemorrhage, $b=$ the greatest length of hemorrhage, and $c=$ the number of slices of hemorrhage. The estimation of hemorrhage volume by this formula is performed considering a $1 \mathrm{~cm}$ distance for CT scan slices. Also, Siemens Multi Slice II CT scan device was used. This bleeding volume was compared to that obtained in 
CT scan 24 hours later. All patients were followed up during transport from ICU to the ward and their ICU stay was calculated in days. Moreover, the cases of deaths during the first 7 days of hospitalization were recorded. Patients with craniotomy before 24 hours after admission were excluded from the study. In this study, tranexamic acid (Tranexipm ${ }^{\circledR}$, from Caspian Tamin Company, Iran) was purchased as $500 \mathrm{mg} 5 \mathrm{cc}$ boluses. For placebo group, 10 cc distilled water was injected into $500 \mathrm{cc}$ normal saline. Injection of the drug or placebo was done at the earliest opportunity after performing CT scan at the time of admission (within the first 8 hours after the trauma). Seeing the hypotension induced by rapid injection of tranexamic acid, this drug was infused intravenously during $1 \mathrm{~h}$ as 1 gr dose diluted in $500 \mathrm{cc} \mathrm{NS}$.

\section{Statistical analysis}

SPSS 20 was used to analyze the culled data using descriptive statistics to describe data and inferential statistics to analyze the research hypotheses. Regarding the subject and nature of hypotheses, independent samples $t$ test, paired samples t test, and ANOVA were used to analyze the quantitative variables, while chi-square test was used to analyze the qualitative variables. $P$ value was set at less than 0.05 , type I error at $\alpha=5 \%$, and test power at $95 \%$.

\section{Results}

In total, 142 patients were assessed for eligibility and 120 were randomized (Fig. 1). The mean age of the patients in tranexamic acid (Group A) and placebo (Group
B) group was $41.15 \pm 20.27$ and $37.40 \pm 19.6$ years, respectively, with the minimum and maximum age of 18 and 85 years, respectively. Also, 20 patients $(20 \%)$ were female, while 80 were male $(80 \%)$.

A total of 56 patients were in the drug group and 44 in the placebo group. Overall, hemorrhage of the epidural hematoma type with 45 cases was the most common type of bleeding in both groups. ICH hemorrhage and IVH hemorrhage with 7 cases each had the least prevalence. The frequency of all types of hemorrhage in both drug and placebo groups is presented in Table 1 and shows a significant difference between the 2 groups regarding the frequency of all types of bleeding $(\mathrm{p}<0.001)$.

A total of 16 female and 40 male patients were in group A, while there were 4 female and 40 male patients in group $\mathrm{B}$, with a significant difference between the 2 groups for this variable (Table 2). Mean cerebral hemorrhage volume at admission detected by $\mathrm{CT}$ scan was 4.9 $\mathrm{cc}$ in group $\mathrm{A}$ and $5.7 \mathrm{cc}$ in group $\mathrm{B}(\mathrm{p}=0.207)$, which demonstrated no significant difference between the 2 . Also, the mean hemorrhage volume at admission was not significantly different between the drug and placebo groups $(p=0.207)$. Moreover, no significant difference was observed in bleeding volume after 24 hours $(\mathrm{p}=$ 0.098). The progress of hemorrhage volume in both groups at admission and 24 hours later was compared pair-wisely and indicated no significant difference in blood volume progress $(\mathrm{p}=0.824)$ (Table 3$)$. Hemorrhage volume at admission and 24 hours later was also calculated for gender and showed no significant difference be-

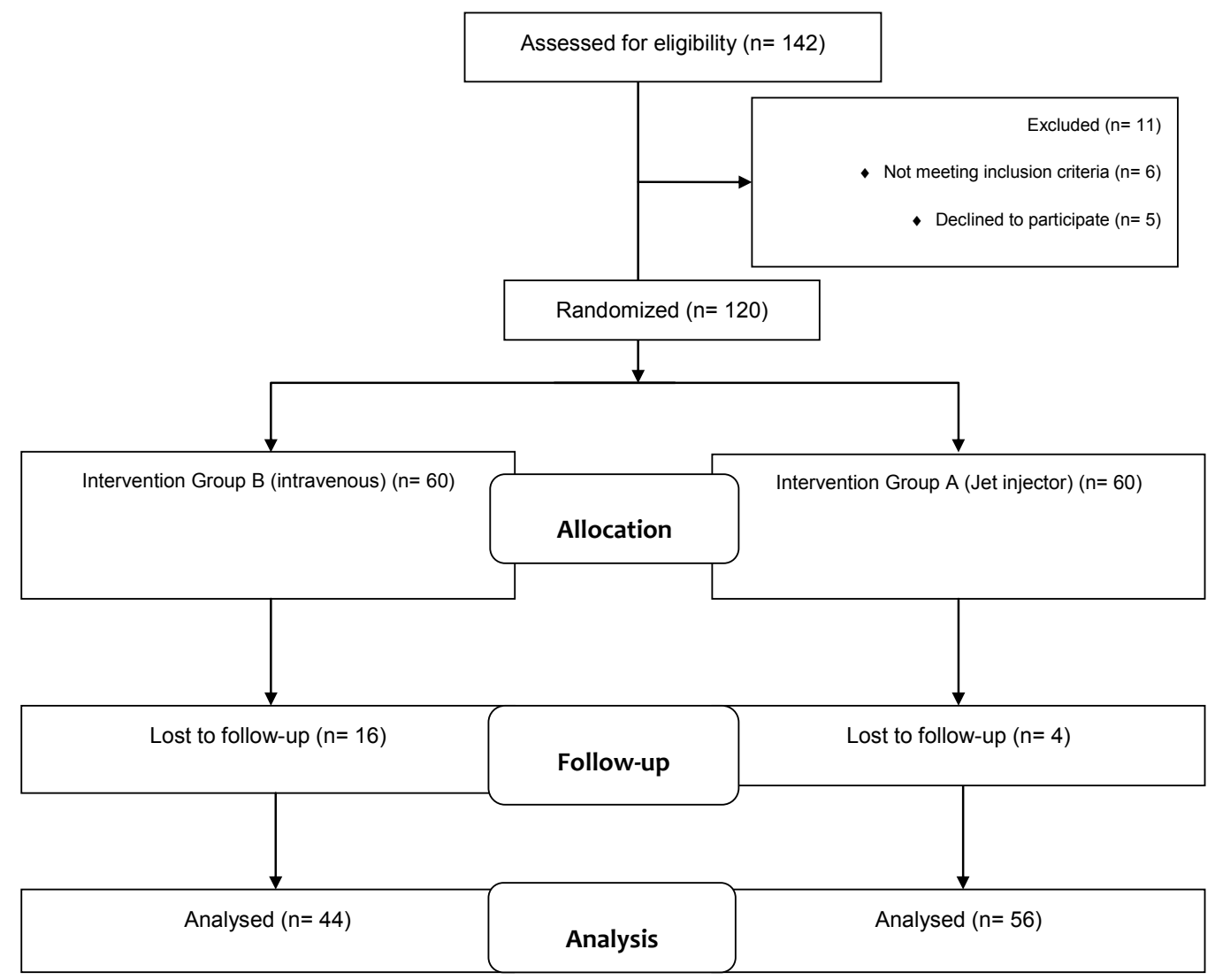

Fig. 1. Flow diagram of the study (according to consort statement) 
Table 1. Frequency distribution of various types of hemorrhage in drug and placebo groups

\begin{tabular}{|c|c|c|c|}
\hline \multirow[b]{2}{*}{$\begin{array}{l}\text { Type of intracranial } \\
\text { hemorrhage }\end{array}$} & \multicolumn{2}{|c|}{ Group } & \multirow[b]{2}{*}{$\begin{array}{l}\text { Total } \\
\mathrm{n}(\%)\end{array}$} \\
\hline & $\begin{array}{c}\text { Tranexamic acid } \\
n(\%)\end{array}$ & $\begin{array}{c}\text { Placebo } \\
\text { n (\%) }\end{array}$ & \\
\hline $\mathrm{EDH}^{\mathrm{a}}$ & $14(25.0 \%)$ & $31(70.4 \%)$ & $45(45.0 \%)$ \\
\hline $\mathrm{SDH}^{\mathrm{b}}$ & $11(19.6 \%)$ & $8(18.18 \%)$ & $19(19.0 \%)$ \\
\hline $\mathrm{ICH}^{\mathrm{c}}$ & $5(8.9 \%)$ & $2(4.5 \%)$ & $7(7.0 \%)$ \\
\hline $\mathrm{IVH}^{\mathrm{d}}$ & $5(8.9 \%)$ & $3(6.8 \%)$ & $8(8.0 \%)$ \\
\hline $\mathrm{EDH}+\mathrm{SDH}$ & $7(12.5 \%)$ & $0(0.0 \%)$ & $7(7.0 \%)$ \\
\hline $\mathrm{SDH}+\mathrm{ICH}$ & $14(25.0 \%)$ & $0(0.0 \%)$ & $14(14.0 \%)$ \\
\hline Total & $56(56.0 \%)$ & $44(44.0 \%)$ & $100(100.0 \%)$ \\
\hline
\end{tabular}

( ${ }^{\mathrm{a}} \mathrm{EDH}$ : epidural hematoma, SDH: subdural hematoma, ICH: intracerebral hemorrhage, IVH: intraventricular hemorrhage).

Table 2. Frequency distribution of various types of variables in drug and placebo groups

\begin{tabular}{|c|c|c|c|}
\hline \multirow[b]{2}{*}{ Variable } & \multirow[b]{2}{*}{ Level } & \multicolumn{2}{|c|}{ Group } \\
\hline & & $\begin{array}{c}\text { Placebo } \\
\mathrm{n}(\%)\end{array}$ & $\begin{array}{c}\text { Tranexamic acid } \\
\mathrm{n}(\%)\end{array}$ \\
\hline \multirow[t]{2}{*}{ Gender } & Female & $4(9.1 \%)$ & $16(28.5 \%)$ \\
\hline & Male & $40(90.9 \%)$ & $40(71.4 \%)$ \\
\hline \multirow[t]{3}{*}{ Coma } & Mild & $28(6.3 .6 \%)$ & $32(57.2 \%)$ \\
\hline & Moderate & $6(13.6 \%)$ & $15(26.7 \%)$ \\
\hline & Severe & $10(22.7 \%)$ & $9(16.1 \%)$ \\
\hline \multirow[t]{2}{*}{ Cause of death } & Head impact & $3(100.0 \%)$ & $4(100.0 \%)$ \\
\hline & Extra cranial bleeding & $0(0.0 \%)$ & $4(100.0 \%)$ \\
\hline Mortality rate & Patients & $3(6.8 \%)$ & $8(16.6 \%)$ \\
\hline Survival rate & Patients & $41(93.2 \%)$ & $48(83.4 \%)$ \\
\hline
\end{tabular}

Table 3. Frequency distribution and mean of various types of variables in drug and placebo groups

\begin{tabular}{|c|c|c|c|c|}
\hline \multirow[b]{2}{*}{ Variable } & \multirow[b]{2}{*}{ Level } & \multicolumn{2}{|c|}{ Group } & \multirow[b]{2}{*}{$\mathrm{p}$} \\
\hline & & $\begin{array}{c}\text { Tranexamic acid } \\
\mathrm{n}=56\end{array}$ & $\begin{array}{c}\text { Placebo } \\
n=44\end{array}$ & \\
\hline \multirow{2}{*}{$\begin{array}{l}\text { Patient's status during } \\
\text { the first } 7 \text { days } \\
\mathrm{n}(\%)\end{array}$} & Death & $8(14.2 \%)$ & $3(6.8 \%)$ & 0.236 \\
\hline & Survival & $48(85.7 \%)$ & $41(93.2 \%)$ & \\
\hline \multicolumn{2}{|l|}{ Mean ICU stay, days $\left(\mathrm{SD}^{\mathrm{a}}\right)$} & $3.589 \pm 4.4$ & $6.659 \pm 4.8$ & 0.001 \\
\hline \multicolumn{2}{|c|}{ Mean hemorrhage volume at admission, days (SD) } & $4.91 \pm 2.8$ & $5.91 \pm 3.4$ & 0.207 \\
\hline \multicolumn{2}{|c|}{ Mean hemorrhage volume after $24 \mathrm{~h}$, days (SD) } & $5.12 \pm 4.6$ & $5.23 \pm 4.1$ & 0.098 \\
\hline
\end{tabular}

${ }^{a}$ Standard deviation

tween the 2 groups at these times, with $\mathrm{P}$ values of 0.903 and 0.282 , respectively. With respect to primary GCS at admission, the patients were divided into 3 groups: mild coma (GCS > 13), moderate coma $(8<\mathrm{GCS} \leq 13)$, and deep coma $(\mathrm{GCS} \leq 8)$. Of all patients, 19 sustained deep coma, 21 moderate coma, and 60 mild coma at admission. The patients who were in the mild coma at admission showed a decreased cerebral bleeding rate after 24 hours; yet, the cerebral hemorrhage volume increased after 24 hours in patients with moderate to severe coma. ANOVA $(\mathrm{p}=0.420)$ indicated a significant change in hemorrhage volume only between mild coma and moderate coma groups. Moreover, no significant difference was detected between primary hemorrhage volume and GCS at admission $(p=0.626)$. The mean ICU stay was 3.5 days in the tranexamic acid group and 6.6 days in placebo group, which revealed a statistically significant difference between the 2 groups $(p<0.001)$. Eight out of 56 patients in the tranexamic acid group and 3 out of 44 patients in the placebo group died. The mean survival rate of patients was 6.5 days in the drug group and 5 days in the placebo group. The 2 groups were not significantly different in mortality rate $(\mathrm{p}=0.236)$. Regarding posthospitalization survival rate, the drug and placebo groups were not significantly different $(\mathrm{p}=0.009)$.

\section{Discussion}

Considering the high prevalence of accidents that led to cephalocranial trauma, much research has been performed on the prevention of secondary injuries and hurts after trauma to the brain. The results of this endeavor have manifested as identification of such factors as hypoglycemia, hypoxia, hyperthermia, and increased ICP with various mechanisms as secondary causes of brain injuries. The identification and treatment of each of these factors will be effective in preventing secondary brain injuries (2). This randomized clinical trial investigated the effect of tranexamic acid with antifibrinolytic and somehow antiinflammatory properties on avoiding the progression of cerebral hemorrhage volume and controlling its associated inflammation in traumatized patients compared to placebo. In addition, the effects of the drug on ICU stay and mortality rate of the patients was explored. Yadav et al (2006) (8) investigated how cerebral hemorrhage volume increased due to trauma. They found that cerebral hemorrhage increased in $37.3 \%$ of the patients, with $90.7 \%$ of cases occurring during the first 24 hours. However, increased hemorrhage occurred in $25 \%$ of our patients, which may be attributed to our intervention. In the study by Yutthakasemsunt et al (2013) (9) in Thailand, hemorrhage volume progress was observed in $18 \%$ and $27 \%$ of the patients in drug and placebo groups, respectively, which indicated no significant difference between the 2 . Our study also obtained similar results. Based on the results of these 2 studies, tranexamic acid has no effect on reducing hemorrhage volume progress. No study has pre- 
viously investigated the correlation between the administration of tranexamic acid and patients' ICU stay. Our study suggested decreased ICU stay for patients in tranexamic acid group $(\mathrm{p}=0.001)$. Considering that all the patients under study were traumatized and comparing our findings to those of CRASH-2 study, it seems that the administration of this drug in traumatized patients reduces their mortality rate and improves their final status. Our findings are indicative of the effectiveness of tranexamic acid in traumatized patients. Nonetheless, secondary analyses on data obtained from CRASH-2 clinical trial revealed that considering the cephalic trauma variable, there was no improvement in trauma-related injuries (10). Cap (2011) (11) reviewed the history of research on the application of tranexamic acid in traumatized patients and found that this cost effective medicine should be included in the guidelines and treatment protocol of traumatized patients. Furthermore, Zehtabchi et al (2014) conducted a meta-analysis at New York University and investigated the effect of administration of tranexamic acid on the final neurologic status, mortality rate, and the subsequent disability in traumatized patients compared to placebo. They concluded that a statistically significant decrease had occurred in cerebral hemorrhage volume of the patients who received tranexamic acid with no ultimate significant improvement in treatment results (12). In this study, we surveyed the mortality rate during the first 7 days after admission and found no significant difference between the drug and placebo groups $(\mathrm{p}=0.236)$. A similar result was obtained by Yutthakasemsunt et al (9); yet, the CRASH-2 study demonstrated a decreased mortality rate in patients who received tranexamic acid (13). The study by Yadav et al (8) explored the factors affecting hemorrhage progress and found that the primary low GCS can serve as a predictor of increased hemorrhage volume. The present study also obtained similar findings in which the patients with mild coma showed a decreasing course of hemorrhage volume during the first 24 hours, while the patients with moderate to severe coma suggested an increasing trend. However, none of the similar clinical trials referred to in our study excluded subarachnoid hemorrhage $(10,12,14)$, while subarachnoid hemorrhage is cited as contraindications of tranexamic acid. Moreover, this study did not explore the complications of this drug based on the results of other studies that indicated no serious or lifethreatening complications of the drug.

This study had the following limitations and weaknesses: the patients were referred to ER of the hospital after 8 hours, especially in cases of trauma in neighboring towns; lack of cooperation in signing informed written consents by the patients or their acquaintances; presence of subarachnoid hemorrhage, along with other types of bleeding as a common incident, which is one of the contraindications of this drug; and age limitations considered for the study. Also, the need for craniotomy before 24 hours excluded the patients from the study.

It is recommended to replicate this study in future considering the following factors: using higher or repeated doses of tranexamic acid; following the progress or reduction rate of hemorrhage after the initial 24 hours; using a larger sample size in a multicenter study; repeating the study considering race, and administering the drug at the prehospital stage.

\section{Conclusion}

Based on our findings, tranexamic acid has no effect on controlling the progress of cerebral hemorrhage volume in traumatized patients. However, it may reduce the patients' ICU stay. Also, it exerts no specific effect on decreasing patients' mortality rate. Another finding of this study was the probable correlation between the rate of hemorrhage volume progress and the patient's initial GCS. The mean hemorrhage volume decreased in moderate coma patients after 24 hours. This finding may introduce the incidence of hemorrhage-related injuries such as concussion, etc. Such injuries can lead to a drop in consciousness level, initiation of specific physiologic and cellular cycles culminating in insufficiency of restorative and modulating systems of the brain, which may cause an increase in cerebral hemorrhage volume.

\section{Acknowledgements}

The authors thank the personnel at Emergency Department of Shahid Rahnemoon hospital in Yazd, central Iran, for their kind cooperation in this study.

\section{Conflict of Interests}

The authors declare that they have no competing interests.

\section{References}

1. Bahadorkhan G. Traumatic intraventricular hemorrhage in severe blunt head trauma: a one year analysis. Med J Islam Repub Iran. 2006;20(1):13-18.

2. Sareml F. Post-traumatic chronic spinal cord injury: Assessment with MRI. Med J Islam Repub Iran. 1995;9(2):83-89.

3. Bidaki R, Zarepur E. Intermittent Hemiplegia in a Boy with Primary Moyamoya Disease: A Case Report from Iran. Iran J Child Neurol. 2017;11(2):65

4. Narayan RK, Maas AI, Servadei F, Skolnick BE, Tillinger MN, Marshall LF. Progression of traumatic intracerebral hemorrhage: a prospective observational study. J Neurotrauma. 2008;25(6):629-39.

5. Zuraw BL. HAE therapies: past present and future. Allergy Asthma Clin Immunol. 2010;6:23.

6. Ozawa H, Abiko Y, Akimoto T. A 50-year history of new drugs in Japan-the development and trends of hemostatics and antithrombotic drugs. Yakushigaku Zasshi. 2003;38(1):93-105.

7. Bruns J, Hauser W. The epidemiology of traumatic brain injury: a review. Epilepsia. 2003;44:Supplement 10:2-10.

8. Yadav YR, Basoor A, Jain G, Nelson A. Expanding traumatic intracerebral contusion/hematoma. J Neurol India. 2006;54(4):377-81.

9. Yutthakasemsunt S, Kittiwatanagul W, Piyavechvirat P, Thinkamrop B, Phuenpathom N, Lumbiganon P. Tranexamic acid for patients with traumatic brain injury: a randomized, double-blinded placebocontrolled trial. BMC Emerg Med. 2013;22:13:20.

10. The CRASH-2 Collaborators. Effect of tranexamic acid in traumatic brain injury: a nested randomised, placebo controlled trial (CRASH-2 Intracranial Bleeding Study). BMJ. 2011;343:d3795.

11. Cap AP, Baer DG, Orman JA, Aden J, Ryan K, Blackbourne LH. Tranexamic acid for trauma patients: a critical review of the literature. J Trauma. 2011;71(1 Suppl):S9-14.

12. Zehtabchi S, Abdel Baki SG, Falzon L, Nishijima DK. Tranexamic acid for traumatic brain injury: a systematic review and meta-analysis. Am J Emerg Med. 2014;32(12):1503-9.

13. The CRASH-2 Collaborators. Effects of tranexamic acid on death, vascular occlusive events, and blood transfusion in trauma patients with significant haemorrhage (CRASH-2): a randomised, placebocon- 
The effect of intravenous tranexamic acid on preventing the progress of cerebral hemorrhage

trolled trial. Lancet. 2010;376(9734):23-32.

14. Dewan Y, Komolafe EO, Mejía-Mantilla JH, Perel P, Roberts I, Shakur H. CRASH-3 Collaborators. CRASH-3 - tranexamic acid for the treatment of significant traumatic brain injury: study protocol for an international randomized, double-blind, placebo-controlled trial. Trials. 2012;21(13):87 